\title{
KUNZE, Thomas, Staatschef a.D. Die letzten Jahre des Erich Honecker
}

\section{Loïc Batel}

\section{OpenEdition}

\section{Journals}

Édition électronique

URL : http://journals.openedition.org/ifha/1221

DOI : 10.4000/ifha.1221

ISSN : 2198-8943

Éditeur

IFRA - Institut franco-allemand (sciences historiques et sociales)

Référence électronique

Loïc Batel, « KUNZE, Thomas, Staatschef a.D. Die letzten Jahre des Erich Honecker », Revue de l'IFHA [En ligne], Date de recension, mis en ligne le 01 janvier 2002, consulté le 22 septembre 2020. URL : http:// journals.openedition.org/ifha/1221; DOI : https://doi.org/10.4000/ifha.1221

Ce document a été généré automatiquement le 22 septembre 2020

(CIFHA 


\title{
KUNZE, Thomas, Staatschef a.D. Die letzten Jahre des Erich Honecker
}

\author{
Loïc Batel
}

Le présent ouvrage est consacré aux derniers moments de l'ancien maître de la RDA Erich Honecker soit de la veille de la réunification (octobre 89) à sa mort le 29 mai 1994. Traité de façon chronologique en 8 chapitres (oct. 89 ; oct. 89-janv. 1990 ; janv. 1990 ; fév.-avril 1990 ; avr. 90-mars 1991 ; mars 91-juillet 1992 ; juillet 1992-jan. 1993 ; jan. 1993-mai 1994) le livre suit pas à pas la fin à la fois pitoyable et misérable d'un homme qui, jusqu'au bout, aura refusé de voir l'histoire en face et de procéder à une libéralisation dont le SED, le parti " unifié », était par ailleurs incapable : le lecteur accompagne ainsi Honecker dans sa destitution, ses inculpations successives, sa fuite à Moscou en mars 91 puis son retour en juillet 92 suivi d'une nouvelle arrestation et d'un procès auquel seule la maladie lui permettra d'échapper. Son exil au Chili et sa mort dans la solitude terminent l'ouvrage.

Sans doute le peu de recul historique vis-à-vis de la période peut-il de prime abord laisser sceptique, un handicap au demeurant dont l'auteur, dans son introduction, a parfaitement conscience. Toutefois, T.K. a simplement voulu reconstituer les derniers faits et gestes de l'ancien secrétaire général du SED : le type de recherches menées (quelques archives, principalement issues des " partis et organisations de masse de RDA " mais surtout de très larges entretiens avec les acteurs contemporains) le style et le traitement journalistiques proposés autant que le caractère lapidaire du titre ne laissent aucun doute à ce sujet. De son propre aveu, T.K. souhaite avant tout apporter sa contribution à une future biographie de Honecker. Un bémol toutefois : outre la présence parfois incongrue de quelques retours en arrière explicatifs trop rapides pour être réellement satisfaisants, on regrettera surtout la brièveté de l'analyse inspirée par le cas Honecker dans une conclusion symbolique (deux pages). Or, la fin d'un tel homme aurait pu permettre une réflexion elle fort utile et nécessaire aux historiens de la RDA tant à propos de l'exemplarité du chef de la RDA que sur d'autres questions de fond (telles la réalité du pouvoir au sein du SED, le problème de la responsabilité pénale des acteurs de la RDA ou encore de l'indépendance d'esprit de la justice dans une 
Allemagne nouvellement réunifiée). Mais peut-être est-ce là davantage le travail d'un ouvrage encore à venir.

Loïc BATEL 